\title{
The Role of Magnetic Resonance Imaging of the Temporomandibular Joint to Investigate Tinnitus in Adults with Temporomandibular Joint Disorder: A Comparative Study
}

\author{
Danielle Lavinsky ${ }^{10}$ Joel Lavinsky ${ }^{2}$ Enio Tadashi Setogutti ${ }^{3}$ Daniela Disconzi Seitenfus Rehm ${ }^{4}$ \\ Luiz Lavinsky ${ }^{1}$
}

${ }^{1}$ Department of Surgical Sciences, Graduate Program in Medicine, Universidade Federal do Rio Grande do Sul, Porto Alegre, RS, Brazil

2 Department of Otorhinolaringology, Clinica Lavinsky, Porto Alegre, RS, Brazil

${ }^{3}$ Department of Magnetic Resonance Imaging, Hospital Ernesto Dornelles, Porto Alegre, RS, Brazil

${ }^{4}$ Department of Temporomandibular Disorder and Orofacial Pain, Associação Brasileira de Odontologia, Porto Alegre, RS, Brazil

\author{
Address for correspondence Danielle Lavinsky, Departamento de \\ Ciências Cirúrgicas, Programa de Pós-Graduação em Medicina, \\ Universidade Federal do Rio Grande do Sul, Rua Quintino Bocaiúva, \\ 673, Porto Alegre, RS, 90440051, Brazil \\ (e-mail: danielle.lavinsky@gmail.com).
}

Int Arch Otorhinolaryngol 2020;24:e68-e72.

\begin{abstract}
Introduction The prevalence of tinnitus is higher in individuals with temporomandibular joint disorder (TMD) than in the general population. Magnetic resonance imaging (MRI) of the temporomandibular joint (TMJ) is the method of choice for investigation, and it has been hypothesized that specific MRI findings might be observed in TMD with comorbid tinnitus.

Objective To comparatively describe MRI findings in patients with TMD with and without tinnitus, identifying the most common TMJ alterations and determining whether a correlation exists between severity of TMD and tinnitus.

Methods A cross-sectional study of 53 adult patients with bilateral or unilateral TMD ( 30 with and 23 without tinnitus). The association between tinnitus and morphological

\section{Keywords}

- magnetic resonance imaging

- temporomandibular joint

- temporomandibular joint disorders

- tinnitus aspects of TMD (changes in condylar morphology, articular eminence morphology, and disc morphology), disc displacement (with/without reduction), condylar translation, and intra-articular effusion was analyzed on MRI images.

Results The mean patient age was $46.12 \pm 16.1$ years. Disc displacement was the most common finding in both groups ( 24 patients with tinnitus versus 15 without; $p=0.043$ ). Only the frequency of disc displacement with reduction was significantly different between groups. Conclusion Additional imaging techniques should be explored to detect specific aspects of the relationship between tinnitus and TMD.
\end{abstract}

\section{Introduction}

The temporomandibular joint (TMJ), which is among the most complex joints in the human body, ${ }^{1}$ is routinely exposed to considerable loads, as indicated by animal, in vitro, and mathematical models. ${ }^{2}$ With time, such exposure, alone or

received

October 26, 2018

accepted

March 17, 2019
DOI https://doi.org/

10.1055/s-0039-1688840. ISSN $1809-9777$. associated with underlying disorders, is thought to generate physiological and pathological changes, ${ }^{3}$ which may lead to temporomandibular joint dysfunction (TMD) of varying complexity and magnitude. ${ }^{4-7}$ The most common symptoms reported by patients with TMD include pain, deviations or restrictions in the range of motion, presence of clicking,

Copyright ( 2020 by Thieme Revinter

Publicações Ltda, Rio de Janeiro, Brazil

License terms

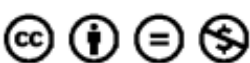


crackling, or popping sounds, ${ }^{8}$ and otologic symptoms such as tinnitus, ${ }^{9}$ defined as a phantom sound in the absence of an external source. ${ }^{10}$

The prevalence of tinnitus is higher in individuals with TMD than in the general population. ${ }^{5}$ Neither TMD nor tinnitus are life-threatening, but both can cause great distress. $^{3,10,11}$ Although the pathogenesis of the relationship between TMD and tinnitus is poorly understood, a common etiological mechanism has been suggested. ${ }^{12}$ Therefore, the investigation of findings peculiar to TMD patients with tinnitus may be useful to clarify the link between these two entities, and may shed light on the mechanisms involved in the onset of TMD and tinnitus.

Magnetic resonance imaging (MRI) of the TMJ is the method of choice for investigation of TMD. ${ }^{13}$ It has been hypothesized that specific MRI findings might be observed in TMD with comorbid tinnitus. ${ }^{14}$ Thus, the aim of the present study was to comparatively describe MRI findings in patients with TMD with and without tinnitus, identifying the most common TMJ alterations and determining whether a correlation exists between the severity of TMD and tinnitus.

\section{Methods}

The project was approved by our local institutional review board. All procedures were in accordance with the 1964 Helsinki declaration and its later amendments or comparable ethical standards.

This cross-sectional comparative study analyzed chart data and imaging findings. All investigators signed a data use agreement that ensured anonymity.

The inclusion criteria were age $>17$ years and diagnosis of TMD, ${ }^{15,16}$ based on clinical symptoms including pain, clicking or crackling sounds, and mandibular opening with deviation. The exclusion criteria were objective tinnitus; tinnitus with a diagnosed etiology; Ménière disease; noise-induced hearing loss, ear surgery, or infections; and abuse of ototoxic medications or substances (furosemide, aspirin) or stimulants. Individuals with certain systemic diseases (diabetes, hypothyroidism) were also excluded.

Between 2009 and 2016, adult patients of both genders, with bilateral or unilateral TMD, were selected for the study. Patients with tinnitus and a clinical history of TMD were referred by their otologist to the investigator (a dentist specializing in TMD and orofacial pain) after other otologic comorbidities had been ruled out. Patients with TMD who did not have tinnitus were either referrals from otologists or other specialists or were walk-ins to our service. All patients in both groups underwent a clinical and dental assessment and MRI evaluation of the TMJ.

\section{TMJ Evaluation}

Temporomandibular joint evaluation was performed by the same examiner (DLB) in all patients. Mandibular range of motion was measured as described by Emshoff et al. ${ }^{15}$ Briefly, maximum opening (measured in $\mathrm{mm}$ from the central maxillary incisor to the opposing mandibular incisor) and lateral excursions (relative to the maxillary midline, with the teeth slightly separated) were evaluated. The TMJ was auscultated with a stethoscope to detect unilateral or bilateral clicks during three openings and three lateral and protrusive movements.

Disc displacement with reduction was identified in the presence of a click in the TMJ during vertical mandibular motion and lateral or protrusive excursions and normal closing with or without clicking, reproducible on two of three occasions. Disc displacement without reduction was defined as a history of sudden reduction in mandibular opening, maximum unassisted mandibular opening $35 \mathrm{~mm}$, and mandibular opening with assistance increased by $3 \mathrm{~mm}$ or less over maximum unassisted opening.

\section{Otologic Evaluation}

Patients reporting tinnitus underwent a full ear, nose and throat (ENT) investigation, including pure tone audiometry, to identify the underlying etiology (ear or systemic disorder). If a retrocochlear disorder was suspected, an evoked potential audiometry was performed. If a systemic cause was suspected, a laboratory workup was performed (metabolic, hormonal, renal function, and autoimmune panels).

\section{MRI}

Bilateral parasagittal and coronal T1- and T2-weighted MRIs of the TMJ, as well as cinematic images, were obtained using an HDXT GE 1,5 Tesla (GE Healthcare, Barueri, SP, Brazil) with open and closed mouth. Magnetic resonance imaging findings of condylar morphology, articular eminence morphology, and disc morphology, disc displacement with or without reduction, condylar excursion, and intra-articular effusion were described by an independent radiologist.

\section{TMD Severity Score}

The association between tinnitus and morphological aspects (changes in condylar morphology, articular eminence morphology, and disc morphology), disc displacement (with or without reduction), condylar translation, and intra-articular effusion was analyzed in MRIs of the TMJ. The selection of these criteria was based on the work of Ahmad et al. ${ }^{17}$

ATMD severity score was created for comparison between the groups with or without tinnitus. Each of the six criteria (changes in condylar morphology, articular eminence morphology, and disc morphology, disc displacement, translation, and intra-articular effusion) received a score of zero (absent), 1 (unilateral), or 2 (bilateral). The sum of the scores (minimum zero, maximum 12) indicated the severity of TMD. The mean TMD scores obtained for patients with tinnitus was then compared with the mean score obtained for patients without tinnitus.

\section{Statistical Analysis}

The sample size was calculated as 44 patients ( $n=22 /$ group), considering $\alpha=5 \%$ and a statistical power of $90 \%$ to detect a difference of one standard deviation(SD) in TMD severity score between groups, with one SD assumed to correspond to 2 score points. 
Data were expressed as frequency of altered MRI findings. The TMD severity score was expressed as mean and SD. The Student $t$-test for independent samples was used to compare group means. The Fisher exact test was used to investigate association between categorical variables. Significance was established at $p<0.05$.

\section{Results}

Fifty-three patients were enrolled in the present study. Of these, 30 had tinnitus (study group) and 23 did not have tinnitus (control group). The mean age was 46.12 years (standard deviation, 16.1 years). Thirty-three patients were women (63.5\%). - Table 1 shows a comparison of age and gender between groups; there were no statistically significant differences.

As shown in - Table 2, disc displacement with reduction was the most common MRI finding in both groups. A statistically significant difference was observed only for the frequency of disc displacement with reduction, which was significantly higher in patients with tinnitus.

-Fig. 1 shows a representative MRI of disc displacement with reduction in a participant from the tinnitus group.

As shown in - Table 3, no between-group difference in TMD severity score was observed.

\section{Discussion}

The present study set out to analyze the existence of specific MRI findings in patients with TMD and tinnitus that could differentiate them from patients with TMD without tinnitus. A few studies so far have analyzed characteristic imaging features of tinnitus, ${ }^{14,18}$ but none has focused specifically on the association of TMD and tinnitus.

Upon analysis of MRI findings in patients with tinnitus and those without, we observed that disc displacement with reduction was significantly more frequent in patients with tinnitus. Historical studies, such as that by Myrhaug, ${ }^{19}$ suggest that tinnitus originates from a temporomandibular dysfunction of muscular origin, which might cause secondary hypertonia of the tensor tympani and tensor veli palatini, thus triggering aural symptoms. The sensory-motor theory, in turn, postulates that tinnitus may be modulated by muscle contractions, such as those that occur on palpation of myofascial trigger points. On the other hand, a classic study ${ }^{20}$ reported the existence of a ligament (the discomalleolar

Table 1 Distribution of age and gender in the overall sample and in the groups with and without tinnitus

\begin{tabular}{|l|l|l|l|l|}
\hline Variable & Overall & $\begin{array}{l}\text { Tinnitus } \\
(\boldsymbol{n}=\mathbf{3 0})\end{array}$ & $\begin{array}{l}\text { No tinnitus } \\
(\boldsymbol{n}=\mathbf{2 3})\end{array}$ & $\boldsymbol{p}$ \\
\hline $\begin{array}{l}\text { Age (years), } \\
\text { mean } \pm \text { SD }\end{array}$ & $46.1 \pm$ & $\begin{array}{l}48.9 \pm \\
15.6\end{array}$ & $\begin{array}{l}42.6 \pm \\
16.4\end{array}$ & $0.172^{\mathrm{a}}$ \\
\hline $\begin{array}{l}\text { Women, } \\
\mathrm{n}(\%)\end{array}$ & 33 & 16 & $\begin{array}{l}17 \\
(73.9)\end{array}$ & $0.247^{\mathrm{b}}$ \\
\hline
\end{tabular}

${ }^{\text {a }}$ Student $t$-test.

${ }^{\mathrm{b}}$ Fisher exact test.
Table 2 Frequency of magnetic resonance imaging findings in patients with temporomandibular joint disorder with and without tinnitus

\begin{tabular}{|c|l|l|l|}
\hline Variable & $\begin{array}{l}\text { Tinnitus } \\
(\boldsymbol{n}=30)\end{array}$ & $\begin{array}{l}\text { No tinnitus } \\
(\boldsymbol{n}=23)\end{array}$ & $p^{\mathrm{a}}$ \\
\hline Condylar morphology & & & 0.719 \\
\hline Unilateral & $3(10.0)$ & $3(13.0)$ & \\
\hline Bilateral & $8(26.7)$ & $8(34.8)$ & \\
\hline $\begin{array}{l}\text { Articular eminence } \\
\text { morphology }\end{array}$ & & & 0.111 \\
\hline Unilateral & $1(3.3)$ & $1(4.3)$ & \\
\hline Bilateral & - & $3(13.0)$ & \\
\hline Disc morphology & $1(3.3)$ & $2(8.7)$ & 0.325 \\
\hline Unilateral & $14(46.7)$ & $14(60.9)$ & \\
\hline Bilateral & & & 0.043 \\
\hline $\begin{array}{l}\text { Disc displacement } \\
\text { with reduction }\end{array}$ & - & $3(13.0)$ & \\
\hline Unilateral & $24(80.0)$ & $12(52.2)$ & \\
\hline Bilateral & $10(33.3)$ & $4(17.4)$ & 0.522 \\
\hline $\begin{array}{l}\text { Intra-articular } \\
\text { effusion }\end{array}$ & $2(6.7)$ & $3(13.0)$ & \\
\hline Unilateral & $1(3.3)$ & $2(8.7)$ & \\
\hline Bilateral & & & \\
\hline $\begin{array}{l}\text { Condylar } \\
\text { translation }\end{array}$ & & & \\
\hline Unilateral & & & \\
\hline Bilateral & & & \\
\hline
\end{tabular}

All variables expressed as means and standard deviations.

Bold indicates statistical significance.

${ }^{\mathrm{a}}$ Fisher exact test for comparison between total (unilateral + bilateral) values.

ligament) that attaches to the malleus, crosses the petrotympanic fissure, and then attaches to the posteromedial aspect of the articular disc and capsule. Thus, excursion of the disc and condyle during mandibular motion could impart mobility to the malleus and alter tension in the tympanic membrane, ${ }^{3}$ which could explain the otologic symptoms, among them tinnitus, experienced by patients with disc displacement. Indeed, the landmark studies of Block, ${ }^{21}$ Ren and Isberg, ${ }^{22}$ and Paparo et al ${ }^{23}$ correlated disc displacement with tinnitus, corroborating the findings of our investigation. Costen, ${ }^{24}$ Coleman, ${ }^{25}$ and Komori et $\mathrm{al}^{26}$ found no relationship between disc displacement without reduction and tinnitus, but did find a correlation in disc displacement with reduction; these findings are consistent with our results. It bears stressing that comparison of prior findings to those of the present study is hindered by the fact that previous studies neither performed objective MRI investigation nor used comparative designs. It should also be noted that a causal relationship between tinnitus and TMD or MRI findings is still hypothetical and has not yet been established in the literature.

The severity scale proposed in the present study can also contribute to further research in the field (i.e., MRI-based 

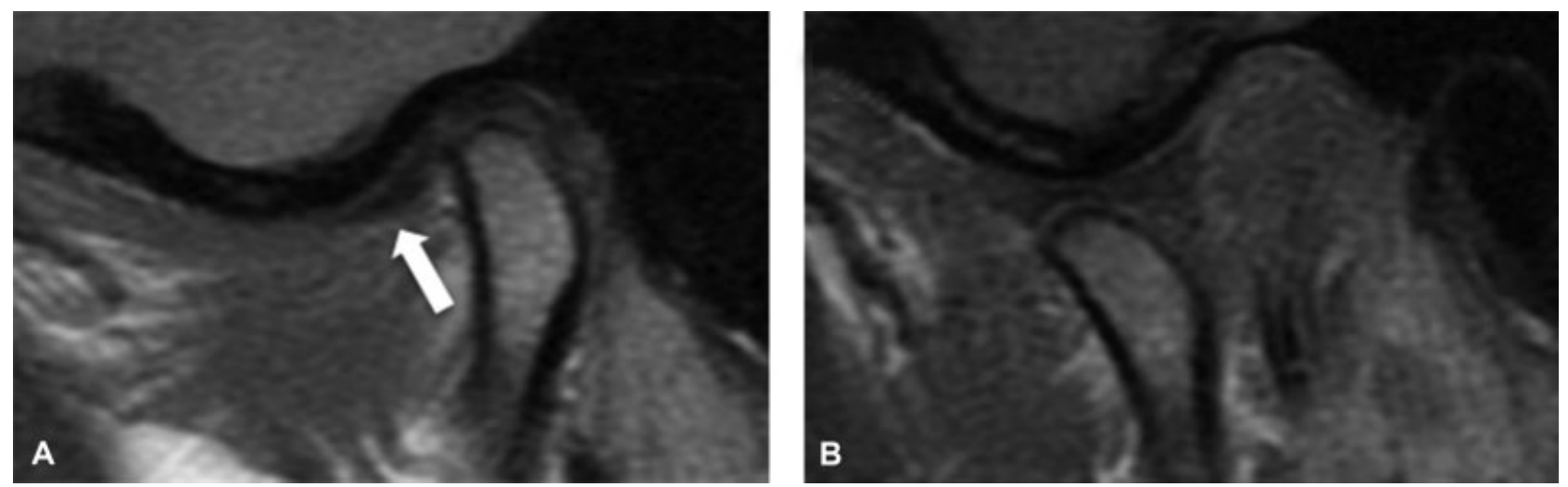

Fig. 1 Parasagittal T1-weighted magnetic resonance imaging of the temporomandibular joint (A, closed mouth; B, open mouth) showing anterior disc displacement (arrow) with reduction.

Table 3 Temporomandibular severity score (mean \pm SD) in patients with and without tinnitus

\begin{tabular}{|l|l|l|}
\hline \multicolumn{2}{|l|}{ TMD severity score } & \multirow{2}{*}{$\boldsymbol{p}^{\mathrm{a}}$} \\
\cline { 1 - 2 } Tinnitus $(\boldsymbol{n}=\mathbf{3 0})$ & No tinnitus $(\boldsymbol{n}=\mathbf{2 3})$ & \\
\hline $5.27 \pm 2.05$ & $5.78 \pm 2.00$ & 0.363 \\
\hline
\end{tabular}

Abbreviations: SD, standard deviation; TMD, temporomandibular joint disorder.

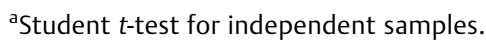

investigation of the relationship between TMD and tinnitus). The mean scores obtained in the groups with and without tinnitus were not significantly different. However, this finding may simply reflect that MRI is unable to discriminate between individuals with tinnitus and those without, which suggests that other imaging criteria, or perhaps even another imaging modality, should be explored for study of the relationship between TMD and tinnitus. Moreover, the fact that nearly all patients with tinnitus and TMD exhibited bilateral disc displacement with reduction (80\% versus $52 \%$ in patients without tinnitus) suggests that this specific abnormality warrants further exploration in future studies with larger samples.

One positive aspect of this study was the homogeneity of gender and age distribution between the groups with and without tinnitus. Another strength was the absence of referral bias, as all patients had been referred to us by otologists after excluding individuals with tinnitus of known etiology. Thus, inclusion in the present study was restricted to patients with clinical symptoms of TMD in whom other comorbidities had been ruled out.

Limitations of this study include the sample size, which, though adequate for the proposed objective, did not allow statistical comparison of subgroups. This may have prevented us from capturing the full dimension of the correlation between severity and prevalence of TMD and tinnitus. Also, a causal relationship between tinnitus and TMD was not established in the present study. However, the present results can serve as a basis for larger prospective studies to shed further light on the relationship between TMD and tinnitus. In addition, further studies are needed on the effect of disc repair on tinnitus, an aspect which was not explored in the present study.

\section{Conclusion}

The present study shows that MRI may not be sufficiently sensitive to detect specific aspects of the relationship between tinnitus and TMD. However, the identification of differences in the prevalence of disc displacement with reduction between individuals with and without tinnitus may provide an important contribution to treatment of these patients, and suggests there is further room to explore the relationship between tinnitus and TMD.

\section{Conflict of Interest}

The authors have no conflicts of interest to disclose.

\section{References}

1 Okeson JP. Management of temporomandibular disorders and occlusion. St. Louis: Elsevier-Mosby; 2013

2 Mercuri LG. Temporomandibular joint total joint replacement TMJ TJR: A comprehensive reference for researchers, materials scientists, and surgeons. Geneva: Springer; 2016

3 Siqueira JT, Teixeira MJ. Dores orofaciais. Diagnóstico e tratamento. São Paulo: Artes Médicas; 2012

4 Lee CF, Lin MC, Lin HT, Lin CL, Wang TC, Kao CH. Increased risk of tinnitus in patients with temporomandibular disorder: a retrospective population-based cohort study. Eur Arch Otorhinolaryngol 2016;273(01):203-208

5 Fernandes G, Siqueira JT, Godoi Gonçalves DA, Camparis CM. Association between painful temporomandibular disorders, sleep bruxism and tinnitus. Braz Oral Res 2014;28:28

6 Hilgenberg PB, Saldanha AD, Cunha CO, Rubo JH, Conti PC. Temporomandibular disorders, otologic symptoms and depression levels in tinnitus patients. J Oral Rehabil 2012;39(04):239-244

7 Taşkaya-Yilmaz N, Oğütcen-Toller M. Magnetic resonance imaging evaluation of temporomandibular joint disc deformities in relation to type of disc displacement. J Oral Maxillofac Surg 2001; 59(08):860-865, discussion 865-866

8 Fernandes G, Gonçalves DA, de Siqueira JT, Camparis CM. Painful temporomandibular disorders, self reported tinnitus, and depression are highly associated. Arq Neuropsiquiatr 2013;71(12):943-947 
9 de Felício CM, Faria TG, da Silva MA, de Aquino AM, Junqueira CA. Temporomandibular Disorder: relationship between otologic and orofacial symptoms. Rev Bras Otorrinolaringol 2004; 70:786-793

10 Allan TW, Besle J, Langers DR, et al. Neuroanatomical Alterations in Tinnitus Assessed with Magnetic Resonance Imaging. Front Aging Neurosci 2016;8:221

11 Henry JA, Dennis KC, Schechter MA. General review of tinnitus: prevalence, mechanisms, effects, and management. J Speech Lang Hear Res 2005;48(05):1204-1235

12 Hilgenberg PB. Estudo da participação de sinais e sintomas de Disfunção Temporomandibular (DTM) e sintomas otológicos em pacientes portadores de zumbido subjetivo [masters thesis]. Bauru: Universidade de São Paulo; 2009

13 Ferreira LA, Grossmann E, Januzzi E, de Paula MV, Carvalho AC. Diagnosis of temporomandibular joint disorders: indication of imaging exams. Rev Bras Otorrinolaringol (Engl Ed) 2016;82(03): 341-352

14 Vattoth S, Shah R, Curé JK. A compartment-based approach for the imaging evaluation of tinnitus. AJNR Am J Neuroradiol 2010;31 (02):211-218

15 Emshoff R, Brandlmaier I, Bertram S, Rudisch A. Relative odds of temporomandibular joint pain as a function of magnetic resonance imaging findings of internal derangement, osteoarthrosis, effusion, and bone marrow edema. Oral Surg Oral Med Oral Pathol Oral Radiol Endod 2003;95(04):437-445

16 Truelove EL, Sommers EE, LeResche L, Dworkin SF, Von Korff M. Clinical diagnostic criteria for TMD. New classification permits multiple diagnoses. J Am Dent Assoc 1992;123(04):47-54
17 Ahmad M, Hollender L, Anderson Q, et al. Research diagnostic criteria for temporomandibular disorders (RDC/TMD): development of image analysis criteria and examiner reliability for image analysis. Oral Surg Oral Med Oral Pathol Oral Radiol Endod 2009; 107(06):844-860

18 Leaver AM, Turesky TK, Seydell-Greenwald A, Morgan S, Kim HJ, Rauschecker JP. Intrinsic network activity in tinnitus investigated using functional MRI. Hum Brain Mapp 2016;37(08):2717-2735

19 Myrhaug H. The incidence of ear symptoms in cases of malocclusion and temporo-mandibular joint disturbances. $\mathrm{Br} \mathrm{J}$ Oral Surg 1964;2(01):28-32

20 Pinto OF. A new structure related to the temporomandibular joint and middle ear. J Prosthet Dent 1962;12:95-103

21 Block LS. Diagnosis and treatment of disturbances of the temporomandibular joint especially in relation to vertical dimension. J Am Dent Assoc 1947;34(04):253-260

22 Ren YF, Isberg A. Tinnitus in patients with temporomandibular joint internal derangement. Cranio 1995;13(02):75-80

23 Paparo F, Fatone FM, Ramieri V, Cascone P. Anatomic relationship between trigeminal nerve and temporomandibular joint. Eur Rev Med Pharmacol Sci 2008;12(01):15-18

24 Costen JB. A syndrome of ear and sinus symptoms dependent upon disturbed function of the temporomandibular joint. 1934. Ann Otol Rhinol Laryngol 1997;106(10 Pt 1):805-819

25 Coleman RD. Temporomandibular joint: relation of the retrodiskal zone to Meckel's cartilage and lateral pterygoid muscle. J Dent Res 1970;49(03):626-630

26 Komori E, Sugisaki M, Tanabe H, Katoh S. Discomalleolar ligament in the adult human. Cranio 1986;4(04):299-305 